\title{
Electron probe microanalysis of ion exchange of selected elements between dentine and adhesive restorative materials
}

\author{
GM Knight,* JM McIntyre,* GG Craig, $†$ Mulyani*
}

\begin{abstract}
Background: There have been numerous attempts to demonstrate the phenomenon of ion exchange between auto cure glass ionomer cements (GICs) and dentine. The purpose of this study was to employ an electron probe microanalysis (EPMA) technique to examine the interchange of elements between non-demineralized dentine and two types of restorative material, auto cure GICs and a resin composite.
\end{abstract}

Methods: Restorations of auto cure GICs (Riva Fast, Fuji IX Fast, Ketac Molar Quick and Fuji VII) and a bonded composite resin were placed in each of 10 recently extracted human third molar teeth. After two weeks the restorations were sectioned and prepared for EPMA. Percentage weights of calcium, phosphorus aluminum, strontium and fluoride were calculated in the restorations $200 \mu \mathrm{m}$ from the restorative interface and $200 \mu \mathrm{m}$ into the dentine at $5 \mu \mathrm{m}$ intervals.

Results: There was evidence of calcium and phosphorus in all five auto cure GICs to a depth of $50 \mu \mathrm{m}$. Aluminum and strontium ions were also present in dentine except subjacent to Ketac Molar restorations. There was evidence of element transfer into composite resin and resin-bonded dentine.

Conclusions: The findings of this paper support the concept of ion exchange as a bonding mechanism between auto cure GIC and dentine. Element penetration into tooth structure and GIC exceeded beyond the "ion exchange layer" observed in scanning electron microscopy studies. Penetration of calcium and phosphorus into composite resin from dentine likely occurred as a result of the self-etching process dissolving calcium and phosphorus and incorporating these elements into the hybrid layer. The presence of $\mathrm{Al}$ and $\mathrm{Sr}$ ions in dentine were likely to be associated with resin tags extending into the dentine.

\footnotetext{
"School of Dentistry, Faculty of Health Sciences, The University of Adelaide.

†Former Associate Professor, Preventive Dentistry, The University of Sydney.
}

Key words: Dentine, auto cure glass ionomer cement, ion exchange.

Abbreviations and acronyms: $\mathrm{EPMA}=$ electron probe microanalysis; GIC = glass ionomer cement; $\mathrm{SEM}=$ scanning electron microscopy.

(Accepted for publication 21 August 2006.)

\section{INTRODUCTION}

Since Wilson et al. ${ }^{1}$ postulated the bonding mechanism of auto cure glass ionomer cement (GIC) to tooth structure there have been a number of attempts using different mechanisms to verify this bond. Watson et $a l^{2,3}$ used fluorescent dyes in GICs to demonstrate the possibility of ion exchange, Lin et al. ${ }^{4}$ looked at the bond using secondary ion mass spectrometry and Ngo et al. ${ }^{6}$ used a cryo scanning electron microscopy to demonstrate the existence of an interaction zone at the dentine restorative interface that resisted acid etching suggesting the existence of an ion-enriched layer. Yoshida et al. ${ }^{5}$ confirmed ionic bonding between the carboxyl ions from the cement and calcium and phosphorus ions within the tooth using X-ray photon spectrometry. Using an electron probe microanalysis (EPMA) ${ }^{7}$ technique $\mathrm{Ngo}^{8}$ was able to demonstrate the transfer of strontium and fluoride ions from auto cure GICs into demineralized dentine. This result has been confirmed by other studies..$^{9,10}$

The purpose of the study was to employ a similar protocol used by $\mathrm{Ngo}^{8}$ to examine the transfer of specific elements (calcium, strontium, aluminum, phosphorus and fluoride) ${ }^{11}$ between auto cure GICs and non-demineralized dentine and between composite resin restorative materials and non-demineralized dentine.

\section{MATERIALS AND METHODS}

Ten recently extracted human third molar teeth that had been stored in $0.5 \%$ chloramine were cut horizontally into sections about $5 \mathrm{~mm}$ thick so as to incorporate the cemento-enamel junction. Teeth were 
collected within the guidelines set by the Committee for the Ethics of Human Experimentation at The University of Adelaide. Five cavities of about $2 \mathrm{~mm}$ diameter and $2.5 \mathrm{~mm}$ deep were prepared at the enamel dentine interface so that the bases of each preparation were in dentine.

\section{Restoration placement prior to experimentation}

Each cavity preparation was restored as follows: (1) The cavity was treated with SE Bond (Kurrary, Tokyo, Japan) according to the manufacturer's instructions and a composite resin (Ice, Southern Dental Industries Melbourne, Australia) was placed into the preparation and photo cured for 10 seconds; (2) The cavity was conditioned with GC conditioner (GC Corporation, Tokyo, Japan) for 10 seconds, washed and dried with oil-free air. Into this preparation a GIC (Riva Fast, SDI) was placed and allowed to set; (3) The cavity was conditioned with GC conditioner for 10 seconds, washed and dried with oil-free air. Into this preparation a GIC (Fuji IX Fast, GC) was placed and allowed to set; (4) The cavity was conditioned with GC conditioner for 10 seconds, washed and dried with oilfree air. Into this preparation a GIC (Ketac Molar Quick, 3M ESPE, Minneapolis, USA) was placed and allowed to set; (5) The cavity was conditioned with GC conditioner for 10 seconds, washed and dried with oilfree air. Into this preparation a GIC (Fuji VII, GC) was placed and allowed to set.

Each restoration was then finished flush to the tooth surface using fine Emery discs and polished using fine Softlex discs (3M) and stored in an aqueous solution for two weeks.

\section{Specimen preparation for electron probe microanalysis}

After two weeks the samples were sectioned to expose a cross-section of the dentine restoration interface at the cavity base. Each section was then placed in a fixing solution containing $1.25 \%$ glutaraldehyde, $4 \%$ sucrose, $4 \%$ paraformaldehyde in PBS at pH 7.2 (Adelaide Microscopy, Adelaide, Australia) for 12 hours, placed into a washing buffer solution, containing PBS, 4\% sucrose (Adelaide Microscopy) for 1.5 hours with changes every 30 minutes. Samples were then dehydrated with ascending grades of ethanols $(25 \%$ ethanol for 20 minutes, $50 \%$ ethanol for 20 minutes, $75 \%$ ethanol for 20 minutes, $95 \%$ ethanol for 30 minutes, $100 \%$ ethanol for one hour).

Dehydrated specimens were placed face down on the base of cylindrical mounting blocks into which epoxy resin 100:25 (Epoxy resin LC 191:Epoxy hardener HY 956) was poured under vacuum and left to set for 24 hours at room temperature. After setting, the specimens were polished using an Abramin polishing machine (Struers, Denmark). The upper and lower surfaces of the mounting blocks were made parallel to each other using a leveling device and the samples mounted on a polisher. The surfaces in which the specimens were embedded were polished using a p80 grit silicone carbide disc (Struers, Denmark) at 150 revolutions per minute ( $\mathrm{rpm}$ ), lubricated with water for 30 seconds under a load of $100 \mathrm{~N}$. The specimen containing surfaces were then polished using p500 grit silicon carbide discs at $150 \mathrm{rpm}$, lubricated with water under a load of $100 \mathrm{~N}$ to grind away the surface resin.

Once the specimen containing surfaces were flat, the surfaces were further polished using diamond polishing discs (Struers) with diamond paste (Kemet, UK). First the surface was polished with $15 \mu \mathrm{m}$ diamond paste on a $15 \mu \mathrm{m}$ diamond polishing disc at $150 \mathrm{rpm}$ for five minutes at $200 \mathrm{~N}$, lubricated with DP-lubricant Green (Struers). After that the surfaces were polished with $3 \mu \mathrm{m}$ (Kemet) and $1 \mu \mathrm{m}$ (Kemet) diamond polishing discs and diamond pastes respectively. Both cycles were at $150 \mathrm{rpm}$ for three minutes at $200 \mathrm{~N}$ and lubricated with DP-Lubricant Green. The surfaces were cleaned with water, air dried and viewed under a stereo microscope (Zeiss, West Germany) at 25x magnification to determine that the embedded specimens had been polished adequately.

The samples were carbon coated for EPMA investigation (CAMECA, SX51, France). Line scans were carried out on the specimens to measure the relative percentage weights of the following elements: calcium $(\mathrm{Ca})$, phosphorus $(\mathrm{P})$, aluminum $(\mathrm{Al})$, strontium $(\mathrm{Sr})$ and fluoride (F). Scans were conducted commencing $200 \mu \mathrm{m}$ within the restoration to the tooth restorative interface and to a depth of $200 \mu \mathrm{m}$ into the dentine every $5 \mu \mathrm{m}$ over a total distance of $400 \mu \mathrm{m}$. One scan was made at each location. The scale of percentage weights were enhanced $75 \mu \mathrm{m}$ either side of the restorative interface to a field height of 5 per cent weight in order to observe more accurately ion transfers close to the restorative interface. Measurements were expressed as a relative percentage weight of the identified element as part of the total weight of the sample where the measurement was taken.

\section{RESULTS}

Figure 1 shows a typical example of the scanning zone of each specimen. Figures 2-4 show the percentage weight of the elements calcium, phosphorus, aluminum, strontium and fluoride detected in the test

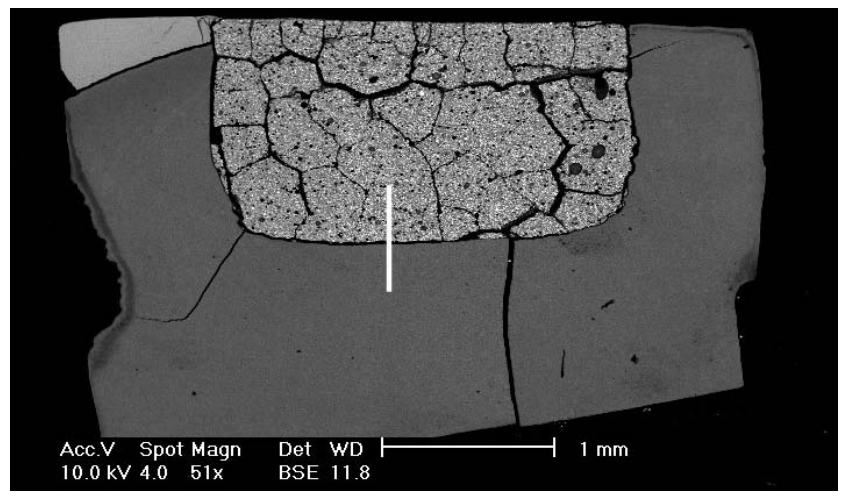

Fig 1. Vertical white lane shows typical scanning range of each sample. 


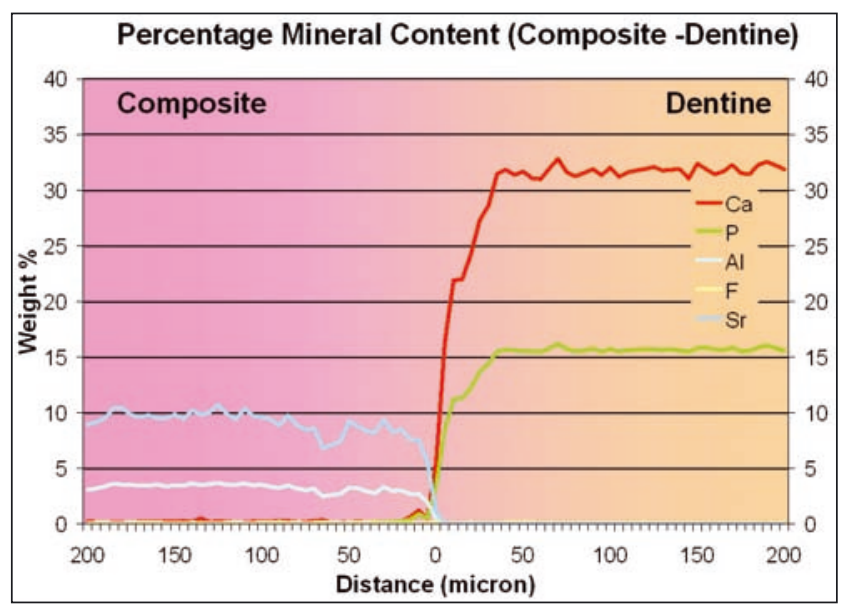

Fig 2a. Element ion transfer of calcium, phosphorus, aluminum, fluoride and strontium between composite resin and dentine. The restorative interface occurs at $0 \mu \mathrm{m}$.

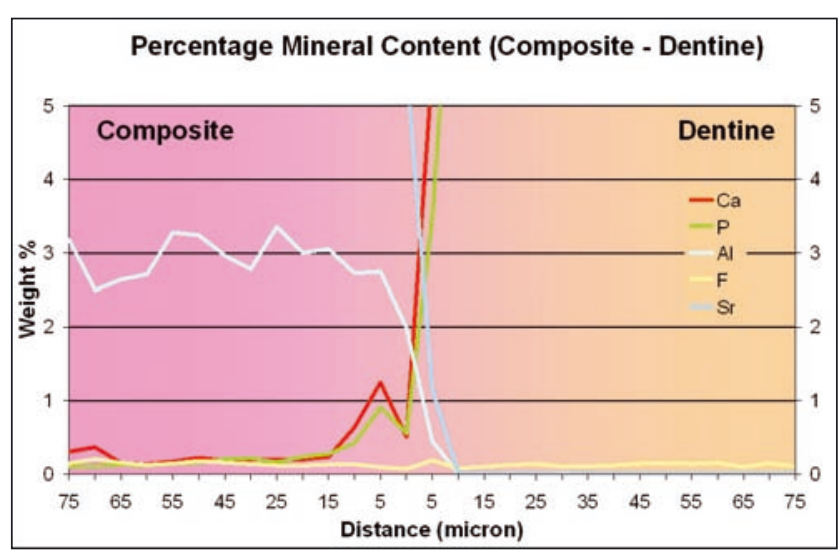

Fig 2b. Element ion transfer of calcium, phosphorus, aluminum,

fluoride and strontium between composite resin and dentine enhanced to a full field of 5 per cent at the restorative interface. The restorative interface occurs at $0 \mu \mathrm{m}$.

restorations and in the subjacent dentine. The distribution of calcium and phosphorus in the body of the dentine in all specimens followed a similar pattern. Calcium was approximately 30 per cent by weight and phosphorus approximately 15 per cent by weight until the interface area where the levels dropped sharply. In the case of the resin composite (Figs $2 \mathrm{a}$ and $2 \mathrm{~b}$ ) there was a slight peak of these elements approximately 7 microns into the restoration zone. With two of the GICs (Riva and Fuji IX) detectable levels of calcium were recorded approximately $70 \mu \mathrm{m}$ into the restoration and detectable levels of phosphorus were seen to the limit of measurement depth.

A similar distribution to the above with respect to calcium and phosphorus were seen in the Ketac Molar specimens with the exception that there were appreciable calcium levels within the body of the restoration (approximately 10 per cent by weight).

Negligible amounts of fluoride were detected in the resin-composite specimens and in all GIC specimens the levels were between 10 and 17 per cent by weight. These levels dropped markedly at the interface area and there was some evidence of fluoride in the subjacent dentine surface zone.

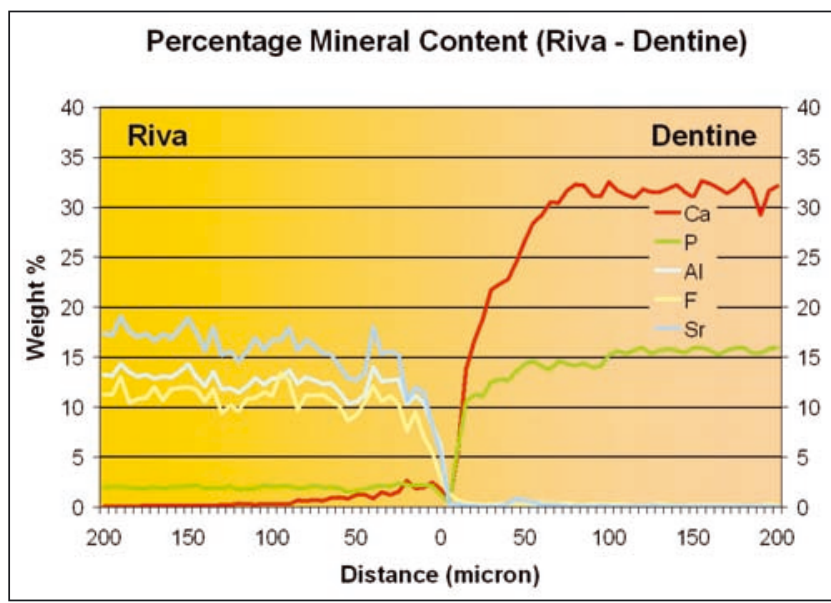

Fig 3a. Element ion exchange of calcium, phosphorus, aluminum, fluoride and strontium between Riva auto cure glass ionomer cement and dentine. The restorative interface occurs at $+15 \mu \mathrm{m}$.

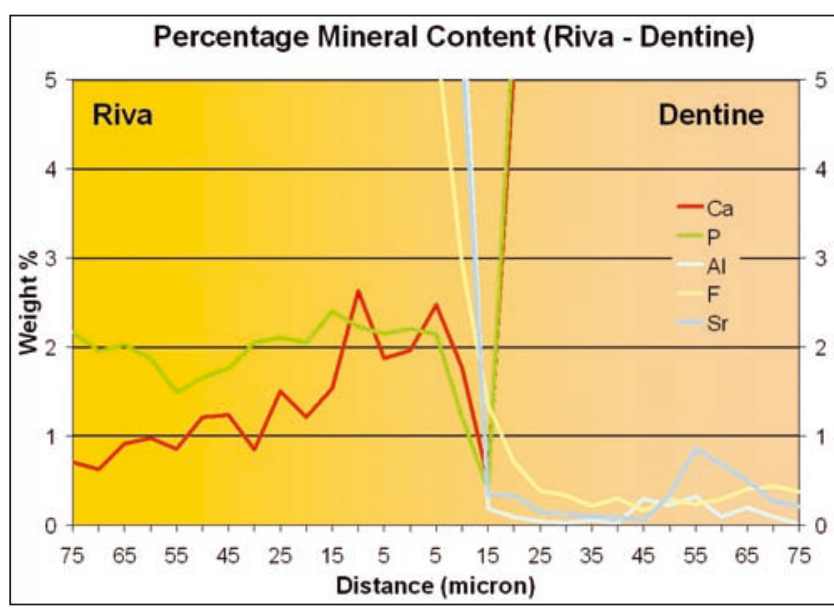

Fig 3b. Element ion exchange of calcium, phosphorus, aluminum, fluoride and strontium between Riva auto cure glass ionomer cement and dentine enhanced to a full field of 5 per cent at the restorative interface. The restorative interface occurs at $+15 \mu \mathrm{m}$.

Strontium was detected in the body of the resincomposite and in two of the GICs (Riva and Fuji IX). The levels were between approximately 10-17 per cent by weight. Towards the interface area the levels dropped sharply and some strontium was detected in the surface zone of the subjacent dentine. The levels of aluminum detected were lower but followed the same general distribution pattern as strontium.

\section{DISCUSSION}

Ionic exchange between tooth structure and an adhesive restorative material requires an aqueous environment in order for ion exchange to occur. ${ }^{12}$ Polyalkenoic acid from the cement is buffered by phosphate ions within the tooth and calcium and phosphate ions are dispersed from the hydroxyapatite into the unset cement. Ions are also able to disperse from the cement into the dentine resulting in an intermediate layer between the unset GIC and hydroxyapatite, referred to as the "ion exchange layer". ${ }^{13}$ Although the so-called ion exchange layer appears no more than several micrometres wide ${ }^{6}$ when 


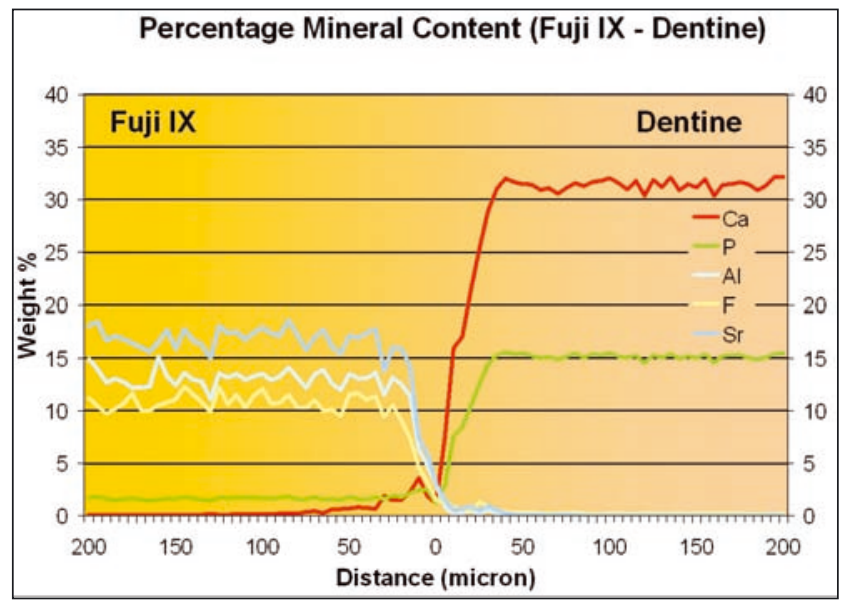

Fig 4a. Element ion exchange of calcium, phosphorus, aluminum, fluoride and strontium between Fuji IX auto cure glass ionomer cement and dentine. The restorative interface occurs at $+5 \mu \mathrm{m}$.

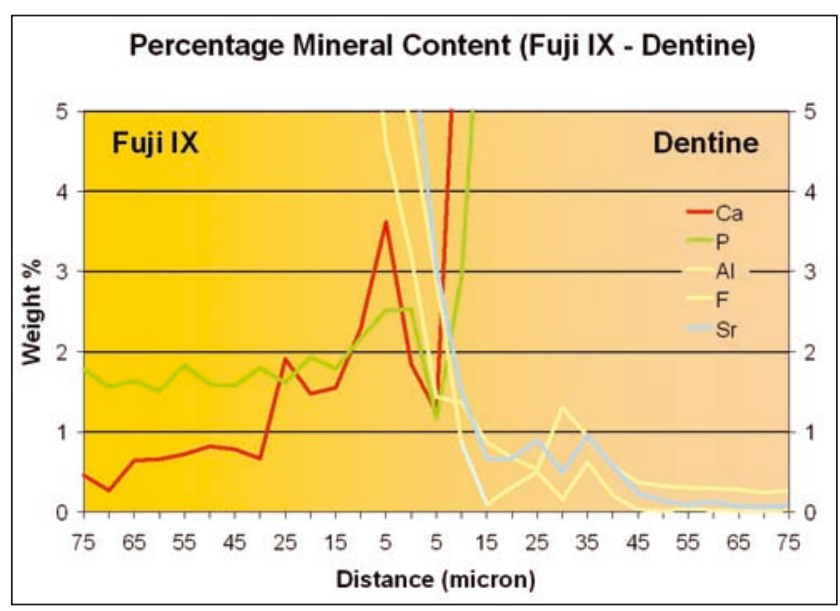

Fig 4b. Element ion exchange of calcium, phosphorus, aluminum, fluoride and strontium between Fuji IX auto cure glass ionomer cement and dentine enhanced to a full field of 5 per cent at the restorative interface. The restorative interface occurs at $+5 \mu \mathrm{m}$.

viewed using scanning electron microscopy (SEM), the penetration of ion exchange observed using EPMA

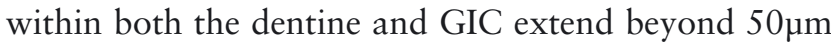
either side of the restorative interface.

Elements such as silicon were not measured and it would be of interest to see how many other elements transfer between the two materials. This raises further questions as to what these characteristics may have on the bond strength and the anecdotal anticariogenic properties of GICs. ${ }^{14}$

The fluoride levels in Ketac Molar are greater than those measured in Fuji IX, Fuji VII and Riva. It is surprising that the amount of fluoride ions transferred into the dentine is similar to the other GICs measured. As Ketac Molar has a calcium-containing glass filler, element transfer is less obvious to observe. However, there is evidence of a slight spike occurring in both the calcium and phosphorus baselines close to the restorative interface that indicates calcium and phosphorus may have become incorporated from the dentine into the Ketac Molar.

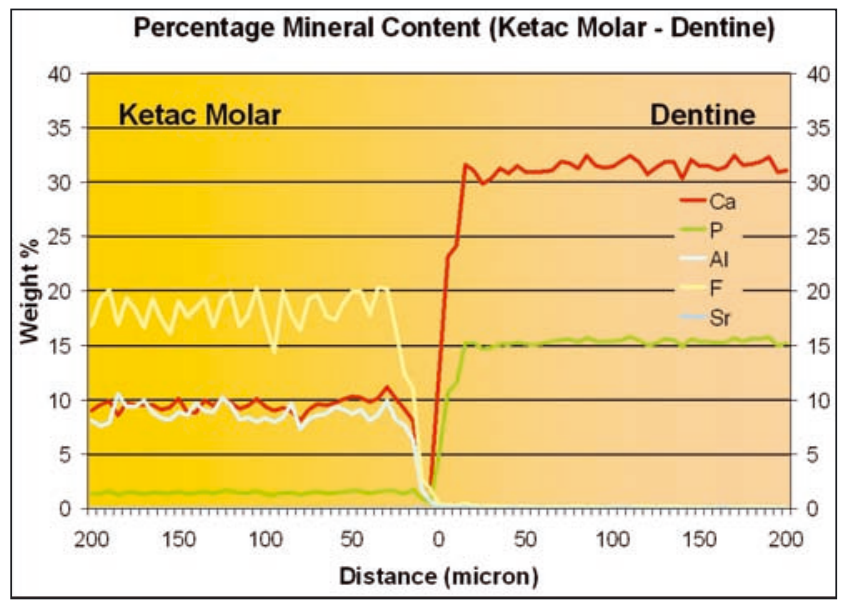

Fig 5a. Element ion exchange of calcium, phosphorus, aluminum, fluoride and strontium between Ketac Molar auto cure glass ionomer cement and dentine. The restorative interface occurs at $0 \mu \mathrm{m}$.

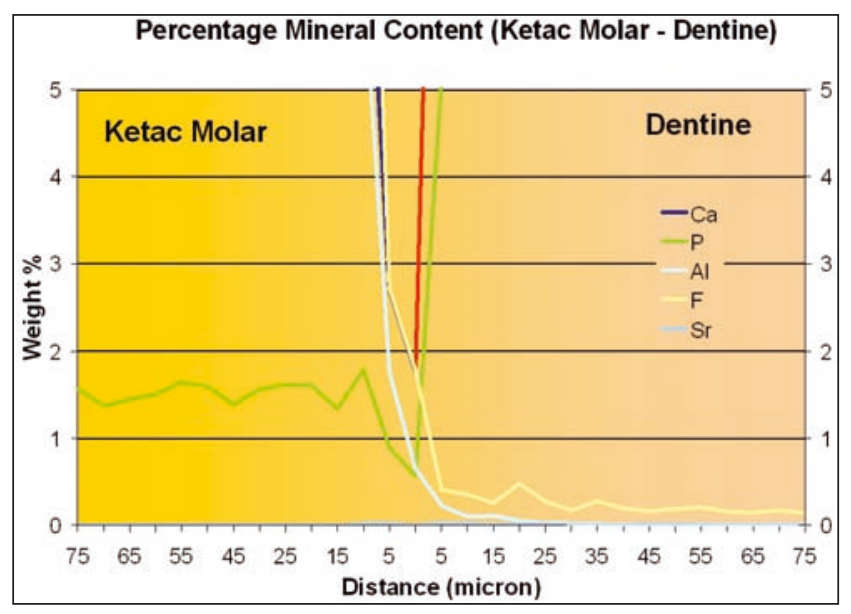

Fig 5b. Element ion exchange of calcium, phosphorus, aluminum, fluoride and strontium between Ketac Molar auto cure glass ionomer cement and dentine enhanced to a full field of 5 per cent at the restorative interface. The restorative interface occurs at $0 \mu \mathrm{m}$.

Fuji VII is promoted as a high fluoride release GIC, yet the amount of fluoride released into the adjacent dentine is similar to that of Fuji IX. This suggests that although more fluoride ions are being released into the environment, there is a limit to the amount of fluoride that is capable of being deposited into dentine from auto cure GICs.

The presence of $\mathrm{Ca}$ and $\mathrm{P}$ ions embedded in the composite resin is intriguing as ion exchange can only occur in an aqueous environment. As SE Bond incorporates a self-etching primer it can be expected that a small amount of calcium and phosphorus dissolved out from the dentine surface during the etching process to become embedded into the composite resin. The extent that this may have on weakening the resin dentine bond is unknown.

The $\mathrm{Sr}$ and $\mathrm{Al}$ elements in dentine subjacent to the composite resin may have been derived from the inorganic filler fraction of the material. Studies using self-etching primers for dentine bonding on extracted human teeth have shown extensive penetration of resin 


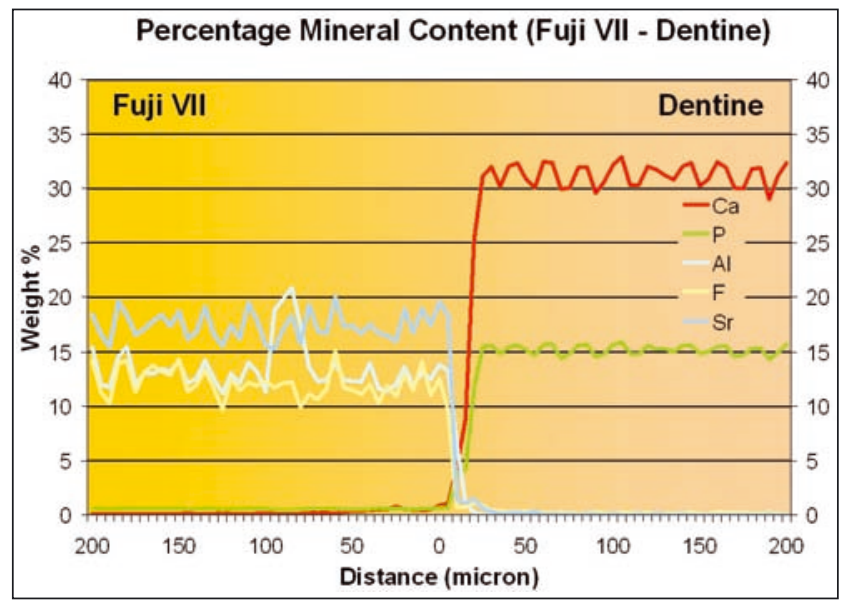

Fig 6a. Element ion exchange of calcium, phosphorus, aluminum, fluoride and strontium between Fuji VII auto cure glass ionomer cement and dentine. The restorative interface occurs at $0 \mu \mathrm{m}$.

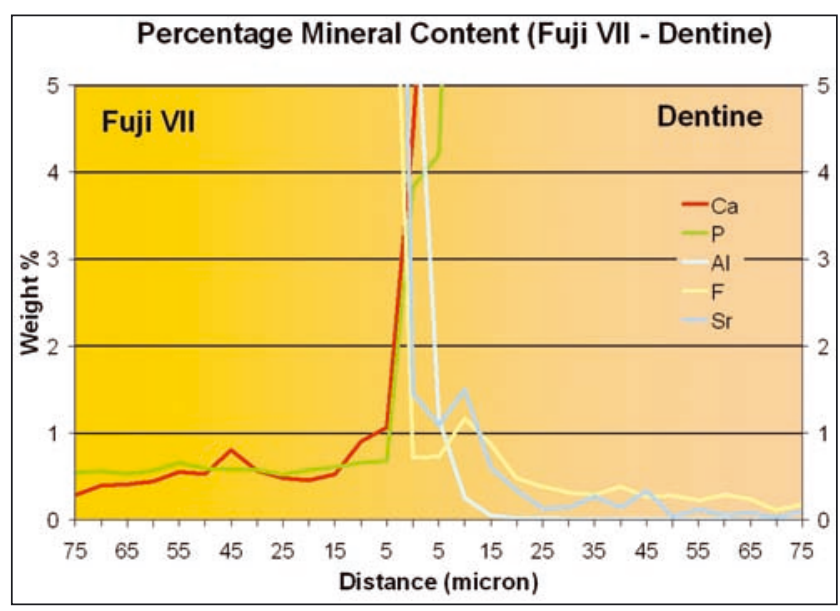

Fig 6b. Element ion exchange of calcium, phosphorus, aluminum, fluoride and strontium between Fuji VII auto cure glass ionomer cement and dentine enhanced to a full field of 5 per cent at the restorative interface. The restorative interface occurs at $0 \mu \mathrm{m}$.

tags into the dentine tubules. ${ }^{15}$ Whether the $\mathrm{Sr}$ and $\mathrm{Al}$ elements followed such a pathway is not known.

This pilot study supports the bank of evidence of a chemical bond between tooth structure and auto cure GICs and furthers confidence amongst dentists in the clinical application of this material.

\section{CONCLUSIONS}

The findings of this paper support the concept of ion exchange as a bonding mechanism between auto cure GIC and dentine. Using EPMA the penetration of elements from tooth structure and GIC were found to exceed well beyond the confines of the "ion exchange layer" observed in previous SEM studies. Penetration of calcium and phosphorus into composite resin from dentine likely occurred following self-etch priming whilst the $\mathrm{Al}$ and $\mathrm{Sr}$ elements seen in the subjacent dentine may have been derived from the inorganic filler fraction of the material.

\section{ACKNOWLEDGEMENTS}

The authors gratefully acknowledge Adelaide Microscopy for assistance with collecting data for the EPMA.

\section{DISCLOSURE}

The corresponding author was associated with the development of Fuji VII and has a financial interest in this product.

\section{REFERENCES}

1. Wilson AD, Prosser HJ, Powis DM. Mechanism of adhesion of polyelectrolyte elements to hydroxyapatite. J Dent Res 1983;62:590-592.

2. Watson TF, Billington RW, Williams JA. The interfacial region of the tooth/glass-ionomer restoration: a confocal optical microscope study. Am J Dent 1991;4:303-310.

3. Watson TF, Pagliari D, Sidhu SK, Naasan M. Confocal microscopic observation of structural changes in glass-ionomer cements and tooth interfaces. Biomaterials 1998;19:581-588.

4. Lin A, McIntyre NS, Davidson RD. Studies on the adhesion of glass-ionomer cements to dentin. J Dent Res 1992;71:1836-1841.

5. Yoshida Y, Van Meerbeek B, Nakayama Y, et al. Evidence of chemical bonding at biomaterial-hard tissue interfaces. J Dent Res 2000;79:709-714.

6. Ngo H, Mount GJ, Peters MCRB. A study of glass-ionomer cement and its interface with enamel and dentin using a lowtemperature, high-resolution scanning electron microscope technique Quintessence Int 1997;28:63-69.

7. Ngo H, Ruben J, Arends J, et al. Electron probe microanalysis and transverse microradiography studies of artificial lesions in enamel and dentin: a comparative study. Adv Dent Res 1997;11:426-432.

8. Ngo H. Ion exchange between glass ionomers and demineralized dentine. Adelaide: The University of Adelaide, August 2005. PhD Thesis.

9. Knight GM, McIntyre JM, Craig GG, Mulyani. Ion uptake into demineralized dentine from glass ionomer cement following pretreatment with silver fluoride and potassium iodide. Aust Dent J 2006;51:237-241.

10. Knight GM, McIntyre JM, Craig GG, Mulyani, Zilm PS, Gully NJ. Differences between normal and demineralized dentine pretreated with silver fluoride and potassium iodide after an in vitro challenge by Streptococcus mutans. Aust Dent J 2007;52:16-21.

11. Saito S, Tosaki S, Hirota K. Characteristics of glass-ionomer cements. In: Davidson CL, Mjor IA, eds. Advances in glassionomer cements. Chicago: Quintessence, 1999:15-50.

12. Watson TF. Bonding glass-ionomer cements to tooth structure. In: Davidson CL, Mjor IA, eds. Advances in glass-ionomer cements. Chicago: Quintessence, 1999:121-135.

13. Tyas MJ, Burrow MF. Adhesive restorative materials: a review. Aust Dent J 2004;49:112-121.

14. Forsten L, Mount GJ, Knight GM. Observations in Australia of the use of glass ionomer cement restorative material. Aust Dent J 1994;39:339-343.

15. Cal-Neto JOP, Miranda MS, Dias KRH. Comparative SEM evaluation of penetration of adhesive systems in human dentin with a non-rinse conditioner and a self-etching primer. Braz Dent J 2004;15:19-25.

Address for correspondence/reprints:

Dr GM Knight

20 Carpenter Street

Brighton, Victoria, 3186

Email: geoffbds@dentalk.com.au 